\title{
Alternating Current Electrolysis of Transition-Metal Carbonyl Complexes: Electrochemically Induced Photochemistry
}

\author{
Horst Kunkely, ${ }^{1 \mathrm{a}}$ Andreas Merz, ${ }^{* 1 \mathrm{~b}}$ and Arnd Vogler*1a \\ Contribution from the Institut für Anorganische Chemie and the Institut für Organische Chemie, \\ Fachbereich Chemie und Pharmazie der Universität Regensburg, Universitätsstrasse 3I, \\ D-8400 Regensburg, Federal Republic of Germany. Received June 16, 1983
}

\begin{abstract}
The complex ligand trans-4-styrylpyridine (trans-SP) is converted into its cis isomer (cis-SP) in the coordinated state upon simple alternating current electrolysis of the rhenium complex $\operatorname{Re}\left[(\text { trans-SP })_{2}(\mathrm{CO})_{3} \mathrm{Cl}\right]$ in acetonitrile $/ \mathrm{Bu}_{4} \mathrm{NClO}_{4}$ in an undivided electrochemical cell. Evidence is presented that this reaction proceeds via an electronically excited state of the complex generated by a cation-anion annihilation process. By the same method a $\mathrm{CO}$ vs. $\mathrm{CH}_{3} \mathrm{CN}$ ligand exchange is achieved with chromium hexacarbonyl.
\end{abstract}

New mechanisms of ligand substitution reactions at transition-metal complexes recently have been reported ${ }^{2}$ which are characterized by electron-transfer reactions as key steps although the overall reactions are not redox processes, e.g.,

$$
\begin{gathered}
\mathrm{ML}+\mathrm{e} \rightarrow \mathrm{ML}^{-} \\
\mathrm{ML}^{-}+\mathrm{L}^{\prime} \rightarrow \mathrm{ML}^{\prime-}+\mathrm{L} \\
\mathrm{ML}^{\prime-} \rightarrow \mathrm{ML}^{\prime}+\mathrm{e} \\
\text { overall: } \quad \mathrm{ML}+\mathrm{L}^{\prime} \rightarrow \mathrm{ML}^{\prime}+\mathrm{L}
\end{gathered}
$$

where $M L$ represents a metal-to-ligand bond and $\mathrm{L}^{\prime}$ a substituting ligand.

The initial generation of the substitutionally labile oxidation state of ML can be achieved electrochemically ${ }^{2 a-d}$ or photochemically. ${ }^{2 e}$ The latter way is viable if an electronically excited state of ML can be quenched by electron transfer to or from a suitable quencher, which in the most elegant form is the exchanging ligand itself. Observed Faradaic or quantum efficiencies greater than 1, respectively, show that these reactions are catalytic radical chain reactions. ${ }^{3}$

The reverse process of photoinduced electron transfer, the generation of molecules in an electronically excited state by electron-transfer reactions, is possible if the energy gap between the associated redox potentials exceeds the excitation energy of one of the newly formed species. A well-known example, visible in a literal sense, is the observation of electrochemoluminescence (ecl) of certain aromatic hydrocarbons (e.g., rubrene) and transition-metal complexes (e.g., $\mathrm{Ru}(\text { bpy })_{3} \mathrm{Cl}_{2}$ ) on alternant generation of their oxidized and reduced states at an electrode surface by cation-anion annihilation. ${ }^{4}$ In a typical experiment, the electrode potential is periodically stepped or cycled between the two values $E_{1}$ and $E_{2}$ sufficient to reduce and oxidize a substrate A (Scheme I). Under suitable conditions ecl occurs at both electrodes in a simple undivided cell supplied with alternating current.

It should likewise be possible to observe "photochemical" reactions stemming from such electrochemically generated excited-state molecules. This would add a new type of electron transfer driven reactions to those described above. Although similar re-

(1) (a) Institut für Anorganische Chemie. (b) Institut für Organische Chemie.

(2) (a) Bezens, G. J.: Rieger, P. H.; Visco, S. J. Chem. Soc., Chem. Commun. 1981, 265. (b) Hershberger, J. W.; Kochi, J. K. Ibid. 1982, 212. (c) Derchen, A.; Mahe, C.; Patin, H. Ibid. 1982, 243. (d) Grobe, J.; Zim. mermann, H. Z. Naturforsch. B: Anorg. Chem., Org. Chem. 1981, 36B, 301. (e) Summer, D. P.; Luong, J. C.; Wrighton, M. S. J. Am. Chem. Soc. 1981, 103, 5238 .

(3) Hershberger, J. W.; Klingler, R. J.; Kochi, J. K. J. Amer. Chem. Soc 1983, 105, 61. For related reactions in organic chemistry, see: Saveant, J. M. Acc. Chem. Res, 1980, 13, 323 .

(4) Faulkner, L. R.; Bard, A. J. In "Electroanalytical Chemistry"; Bard A. J., Ed.; Marcel Dekker Inc.: New York, 1977; Vol. 10, p 1.
Scheme I

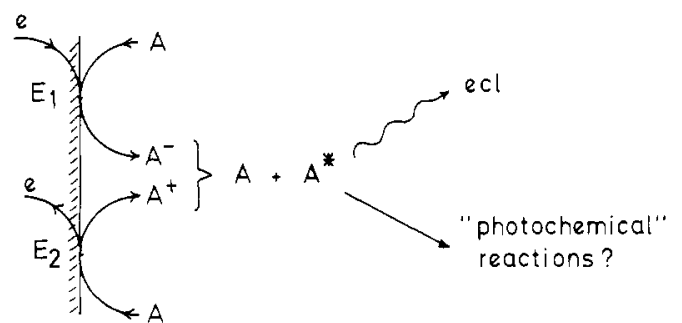

Scheme II
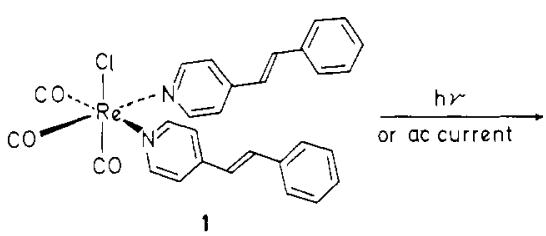

$$
\mathrm{Cr}(\mathrm{CO})_{6}+\mathrm{CH}_{3} \mathrm{CN}
$$

3

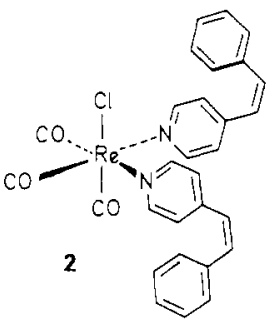

$\mathrm{Cr}(\mathrm{CO})_{5} \mathrm{CH}_{3} \mathrm{CN}+\mathrm{CO}$

4 actions have been postulated, ${ }^{5}$ to our knowledge, real examples have not yet been reported. Substrates suitable for this kind of investigation should give clean intramolecular photochemical reactions and should not show excessive deactivation of the excited state by luminescence or radiationless decay.

We report here on simple ac electrolyses of two transition-metal carbonyl complexes $\mathbf{1}$ and $\mathbf{3}$ giving rise to ligand-sphere reactions that do exactly match the corresponding photochemical conversion (Scheme II).

\section{Experimental}

Materials. $\operatorname{Re}\left[(\text { trans-SP })_{2}\left(\mathrm{CO}_{3} \mathrm{Cl}\right]\right.$ (1) was prepared according to the published procedure. ${ }^{6}$ The cis isomer 2 was obtained from 1 by $366-\mathrm{nm}$ irradiation in acetonitrile $(1 \mathrm{~g}$ in $100 \mathrm{~mL}$, Hanovia Xe/Hg $977 \mathrm{~B}-1$ (1000 W) lamp, Schoeffel GM 250-1 monochromator); the photostationary state with $>95 \%$ trans to cis conversion was reached in $30 \mathrm{~min}$. The $\mathrm{UV} / \mathrm{vis}$ spectra of 1 and 2 agreed well with those reported in the literature. ${ }^{6}$

Commercially available chromium hexacarbonyl (3), was purified by vacuum sublimation

Acetonitrile for photochemical measurements was spectro grade and deaerated by argon. For the electrochemical experiments this solvent was

(5) Park, S. M.: Bard, A. J. Chem. Phys. Lett. 1976, 38, 257

(6) Wrighton, M. S.; Morse, D. L.; Pdungsap, L. J. Am. Chem. Soc. 1975 97,2073 . 


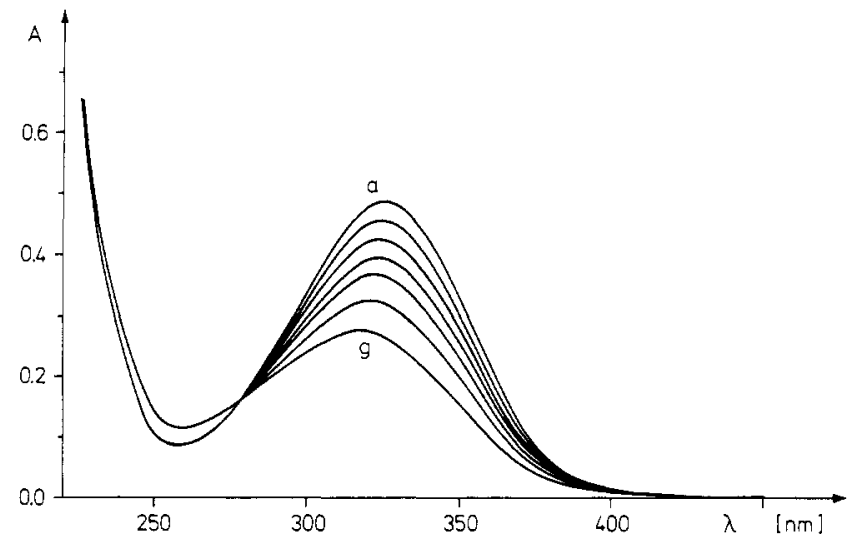

Figure 1. Spectral changes during ac electrolysis of $9.8 \times 10 /^{-6} \mathrm{M} 1$ in acetonitrile/TBAP at (a) 0 and (g) $40 \mathrm{~min}$ electrolysis time, $1-\mathrm{cm}$ cell.

triple vacuum line distilled from $\mathrm{P}_{4} \mathrm{O}_{10}$ and degassed by several freezethaw cycles. The supporting electrolyte $\mathrm{Bu}_{4} \mathrm{NClO}_{4}$ (TBAP) was recrystallized from $65 \%$ ethanol and dried in vacuo.

Equipment and Methods. Photolyses and ac electrolyses were carried out under argon in $1-\mathrm{cm}$ quartz spectrophotometer cells which, in the latter case, were equipped with two platinum foil electrodes directly connected to a Kröncke Model 1246 sine wave generator as an ac voltage source. Irradiations were performed with an Osram HBO $100 \mathrm{~W} / 2$ mercury arc. For irradiation of 1 the $366-\mathrm{nm}$ mercury line was selected by a Schott PIL 366 interference filter; the irradiation of 3 was confined to the near-UV by a Schott UG $1(2 \mathrm{~mm})$ glass filter.

The progress of photolyses and ac electrolyses was monitored by repetitive UV/vis spectral measurements using a Varian-Techtron Super Scan spectrophotometer. The change of extinction at $330 \mathrm{~nm}$ was used to calculate the amount of the $\mathbf{1} \mathbf{\rightarrow} \mathbf{2}$ isomerization with molar extinction coefficients $\epsilon_{\text {trans }}=48900$ and $\epsilon_{\text {cis }}=26300$. The concentration of $\mathrm{Cr}$ $(\mathrm{CO})_{5}\left(\mathrm{CH}_{3} \mathrm{CN}\right)(4)$ was determined at its absorption maximum $(\lambda 387$ $\mathrm{nm} ; \epsilon 3400)$ where $\mathrm{Cr}(\mathrm{CO})_{6}$ does not absorb.

Electronanalytical experiments (cyclic voltammetry (CV), and chronocoulometry) were carried out under nitrogen in a conventional threecompartment cell with a saturated calomel electrode (SCE) connected to the working electrode compartment via a salt bridge, with acetonitrile/0.1 M TBAP as supporting electrolyte in all cases. The working electrode in CV experiments was a $2-\mathrm{mm}$ Pt disk sealed in soft glass. In the chronocoulometric experiments, the working electrode compartment was equipped with a Pt flag electrode for continuous potential step electrolysis and additionally with a $\mathrm{Pt}$ disk electrode for $\mathrm{CV}$ monitoring. Samples were drawn by syringe for UV/vis analysis. Potential and sweep control as well as current integration were provided by a Princeton Applied Research Model 170 electrochemical system. $i / E$ and $q / t$ curves were recorded on an $X Y$ recorder or a storage oscilloscope.

\section{Results and Discussion}

Ac Electrolyses of $\operatorname{Re}[\text { trans }-\mathrm{SP}]_{2}(\mathrm{CO})_{3} \mathrm{Cl}(1)$. As was shown by Wrighton et al., 6 the complex 1 undergoes a smooth photochemical trans-cis isomerization of the stilbazol ligand upon irradiation with $366-\mathrm{nm}$ light. The reaction can be conveniently monitored by the spectral changes of the irradiated solution. The photochemical reaction proceeds via the lowest excited state that has been shown to be an intraligand state of the stilbazol. ${ }^{6}$

When a solution of 1 in dry acetonitrile containing $0.1 \mathrm{M}$ TBAP is subjected to an alternating voltage $(20 \mathrm{~Hz}, 2.6 \mathrm{~V}$, producing an ac current of $6 \mathrm{~mA}$ ) between two platinum foil electrodes in a $1-\mathrm{cm}$ spectrophotometer cell, the same spectral changes of the solution occur, as in the irradiation experiment. The electrolysis proceeds with a clean isobestic point up to a conversion of $35 \%$ until beginning side reactions prevent further UV monitoring (Figure 1).

These conditions are exactly those that would produce ecl with a suitable substrate. Indeed, the related rhenium complex Re$(o$-phen $)(\mathrm{CO})_{3} \mathrm{Cl}$ containing the bidentate $\alpha$-phenanthroline ligand instead of two SP ligands does show ecl under nearly identical conditions. $^{7}$ It is thus not unreasonable to assume that the observed ligand trans-cis isomerization is brought about by the

(7) Luong, J. C.; Nadjo, L.; Wrighton, M. S. J. Am. Chem. Soc. 1978 100,5790 .

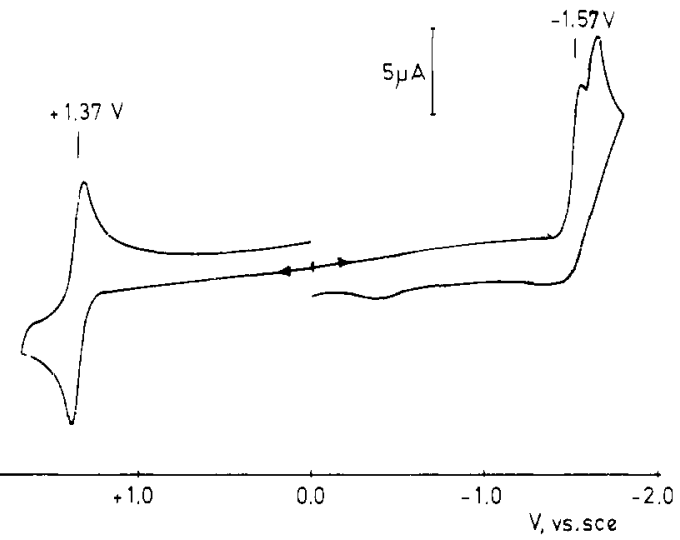

Figure 2. Cyclic voltammograms (reductive and oxidative branch) of $\mathbf{1}$, $6 \times 10^{-4} \mathrm{M}$ in $0.1 \mathrm{M} \mathrm{TBAP} /$ acetonitrile at Pt. Scan rate $=0.2 \mathrm{~V} \mathrm{~s}^{-1}$

excited state generated froom cation-anion annihilation (Scheme I). Light emission cannot be observed in our case since the excited state of 1 , contrary to that of the $o$-phenanthroline complex, is not luminescent. 6 ,

It is, in principle, difficult to prove the intermediate existence of an electronically excited state when there is no emission observable, unless picosecond spectroscopic methods for direct observation of excited states are available. Also, alternatively, the SP ligand could isomerize in the reduced or oxidized state of 1 : isomerizations of free stilbenes and other alkenes from their radical anion or cation states are well-known. ${ }^{8}$

A first support that this is not the case with 1 was obtained by ac electrolyses of 1 in the presence of a tenfold excess of either $N, N, N^{\prime}, N^{\prime}$-tetramethyl-p-phenylenediamine (TMPD, $E_{1 / 2}=+0.12$ and $+0.68 \mathrm{~V}$ vs. $\left.\mathrm{SCE}^{9}\right)$ or $N, N^{\prime}$-dimethyl-4,4'-bipyridinium bis(hexafluorophosphate) ( $\mathrm{MV}^{2+}, E_{1 / 2}=-0.42$ and $-0.83 \mathrm{~V}$ vs. $S C E^{10}$ ). First, these additives serve as redox buffers decreasing the extent of formation of $\mathbf{1}^{-}$or $\mathbf{1}^{+}$, respectively. Furthermore, Wrighton and co-workers have shown that both TMPD and $\mathrm{MV}^{2+}$ are able to quench photoexcited states of the related complex $\operatorname{Re}\left[(o\right.$-phen $\left.)(\mathrm{CO})_{3} \mathrm{Cl}\right]$ by electron-transfer reactions. For both cases we found that the amount of isomerization of $\mathbf{1}$ decreased to less than $15 \%$ of the value for the ac electrolysis of 1 alone. With these findings, the possibility of the cis/trans isomerization occuring in either the reduced or oxidized state of 1 can no longer be taken into account. Further arguments in favor of the excited-state isomerization are obtained by a detailed analysis of the redox behavior of $\mathbf{1}$.

The cyclic voltammorgram of 1 (Figure 2) shows a reversible oxidation wave at $+1.37 \mathrm{~V}, \mathbf{1}^{+}$is stable only on the time scale of cyclic voltammetry; on coulometric generation it decays with a half-life of some minutes yielding electroinactive products. The reduction wave at $-1.57 \mathrm{~V}\left(E_{\mathrm{p} / 2}\right.$ at $\left.0.2 \mathrm{~V} \mathrm{~s}^{-1}\right)$ is irreversible followed closely by a second reduction wave. The voltammogram of the isomeric complex 2 is virtually indistinguishable from the former. The first reduction wave shows beginning reversiblity at $100 \mathrm{~V} \mathrm{~s}^{-1} 1.1^{-}$being a rather short-lived species seems, at first glance, unfavorable for an effective cation-anion annihilation process, but if $\mathbf{1}^{-}$is generated in the presence of $\mathbf{1}^{+}$in the diffusion layer the back electron transfer is expected to proceed at a diffusion-controlled rate and may thus well dominate over alternative reactions of $\mathbf{1}^{-}$. In this context we want to note that the cyclic voltammogram of the above-mentioned $\operatorname{Re}\left[(o\right.$-phen $\left.)(\mathrm{CO})_{3} \mathrm{Cl}\right]$ is quite similar to ours, but ecl does still occur.? The cyclic voltammogram of 1 also shows that the potential difference of $\mathbf{1}^{-}$and $\mathbf{1}^{+}$of $2.94 \mathrm{~V}$ well exceeds the electronic excitation energy of 1 which was estimated to be $2.1 \mathrm{eV} .{ }^{11}$

(8) Cheim, C. U.; Wang, H. C.; Szwarc, M.; Bard, A. J ; Itaya, K. J. Am. Chem. Soc. 1980, 102, 3100 and references cited therein. Yeh, L.-S. R.; Bard, A. J. J. Electrochem. Soc. 1977, 124, 189.

(9) Hand, R.; Melicharek, M.; Scoggin, D. I.; Stotz, R.; Carpenter, A. K.; Nelson, R. F. Collect. Czech. Chem. Commun. 1971, 36, 842.

(10) Osa, T.; Kuwana, T. J. Electroanal. Chem. Interfacial Electrochem. $1969,22,389$ 

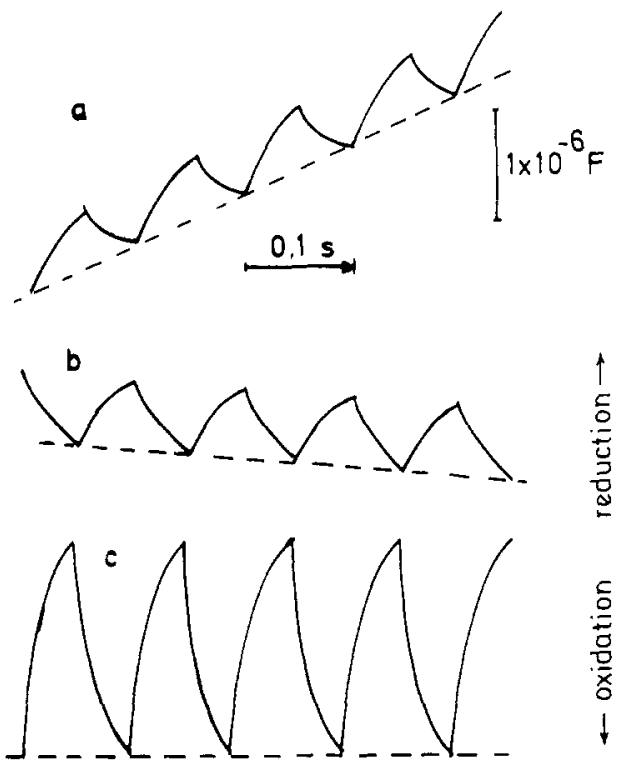

Figure 3. Steady state potential step coulometry of $1\left(7 \times 10^{-3} \mathrm{mmol}\right.$ in $15 \mathrm{~mL}$ of $0.1 \mathrm{M} \mathrm{TBAP} /$ acetonitrile at a $4-\mathrm{cm}^{2} \mathrm{Pt}$ flag). Switching potentials (in V vs. SCE): (a) -1.0 and -1.8 ; (b) +1.6 and +1.0 ; (c) +1.6 and -1.8 . For $a$ and $b$ at the beginning of the electrolysis, for $c$ constant over $2 \mathrm{~h}$.

Continuous potential step chronocoulometric experiments (Figure 3) were studied at a $4-\mathrm{cm}^{2}$ platinum-foil working electrode in a civided cell containing 1 only in the working electrode compartment, with a rectangular wave frequency of $10 \mathrm{~Hz}$ as in the ac experiments without stirring the solution. When the electrode potential was stepped only over the oxidation potential of 1 (without involving the generation of $\mathbf{1}^{-}$) a slow net oxidation of 1 was observed. The corresponding decay of 1 could be followed by periodically measuring the cyclic voltammogram of the solution. Potential steps involving only the reduction wave of 1 led to rapid net reduction. Aliquots of the solution which were taken during the experiments did not reveal any trans-cis isomerization in their UV spectra. The latter occurred only when the potential steps included both reduction and oxidation of $1:$ in this case, over a period of $2 \mathrm{~h}$, no net Faradaic process was observed, the voltammetric peak heights remained constant, and a $45 \%$ conversion of 1 to 2 was detected by UV/vis monitoring of samples.

Again, these experiments show clearly that the isomerization of 1 does not occur from either its oxidized or reduced state. Instead, both cation and anion have to be present in the diffusion layer to promote the isomerization reaction. The similarity in behavior of 1 and $\operatorname{Re}\left[(o\right.$-phen $\left.)(\mathrm{CO})_{3} \mathrm{Cl}\right]$, the former giving isomerization and the latter giving ecl, is, in our belief, a strong support for an excited-state intermediate in both experiments as suggested in Scheme I. As opposed to a possible thermal reaction arising from cation-anion comproportionation, the assumption of an excited-state intermediate is further favored by the direction of the isomerization. Whereas in ref 8 examples of cis-to-trans conversions are described that correspond to the thermal equilibrium, in our case, an energetically uphill trans-to-cis isomerization is observed that is typical for and thus strongly indicative of a "photochemical" reaction.

(11) By sensitization experiments it was shown that energies as low as 2.1 $\mathrm{eV}$ are sufficient to populate the reactive excited state. ${ }^{6}$
A similar analogy between a photochemical reaction and electrolysis by alternating current was observed for 3 . The electrolysis was carried out as described above in deareated acetonitrile with $0.05 \mathrm{M} \mathrm{Bu}_{4} \mathrm{NBF}_{4}$ as supporting electrolyte. An ac current of $5 \mathrm{~mA}$ was produced by an alternating voltage of $2.5 \mathrm{~V} / 10 \mathrm{~Hz}$. Again, the electrolysis was accompanied by the same spectral changes as those observed in the photolysis of 3 in the same solution with 333-nm light. Accordingly, 3 was converted into acetonitrilechromium pentacarbonyl (4). The electrochemically induced ligand exchange was followed to a $28 \%$ conversion.

The electrochemistry of $\mathbf{3}$ has been investigated by Pickett and Pletcher. ${ }^{12} 3$ shows a reversible oxidation wave at $+1.52 \mathrm{~V}$ vs. $\mathrm{SCE}$; the reduction wave at $-2.66 \mathrm{~V}$ is irreversible which was attributed to a rapid or even concerted loss of $\mathrm{CO}$ from $3^{-}$to give $\mathrm{Cr}(\mathrm{CO})_{5}{ }^{-}$. A reverse peak in the cyclic voltammogram at -2.1 $V$ shows the reoxidation of the latter species to the cordinatively unsaturated $\mathrm{Cr}(\mathrm{CO})_{5}$ which can be stabilized by the addition of a solvent molecule as a sixth ligand. Consequently, the observations in our ac experiments can, in this case, be rationalized by the following reaction scheme without invoking an electronically excited 3 in the back-electron transfer:

$$
\begin{gathered}
\mathrm{Cr}(\mathrm{CO})_{6} \rightarrow \mathrm{Cr}(\mathrm{CO})_{6}{ }^{+}+\text {e (anodic cycle) } \\
\mathrm{Cr}(\mathrm{CO})_{6}+\mathrm{e} \rightarrow \mathrm{Cr}(\mathrm{CO})_{6}^{-} \text {(cathodic cycle) } \\
\mathrm{Cr}(\mathrm{CO})_{6}{ }^{-} \rightarrow \mathrm{Cr}(\mathrm{CO})_{5}{ }^{-}+\mathrm{CO} \text { (dissociation) } \\
\mathrm{Cr}(\mathrm{CO})_{6}{ }^{+}+\mathrm{Cr}(\mathrm{CO})_{5}{ }^{-} \rightarrow \\
\mathrm{Cr}(\mathrm{CO})_{6}+\mathrm{Cr}(\mathrm{CO})_{5} \text { (back-electron transfer) } \\
\mathrm{Cr}(\mathrm{CO})_{5}+\mathrm{CH}_{3} \mathrm{CN} \rightarrow \mathrm{Cr}(\mathrm{CO})_{5} \mathrm{CH}_{3} \mathrm{CN} \text { (ligand addition) }
\end{gathered}
$$

However this proposed mechanism is not completely unrelated to that of photodissociation/substitution. The reduction of $\mathbf{3}$ may be compared to the photochemical ligand-field excitation: ${ }^{13}$ in both cases an electron is placed into the antibonding $e_{g}$ orbitals resulting in the release of a $\mathrm{CO}$ ligand.

\section{Concluding Remarks}

In this article we have presented strong evidence for, to our best knowledge, the first example of a "photochemical" reaction with electrochemical generation of the required excited state by alternating current electrolysis. Alternative mechanisms that are feasible for the ac treatment of chromium hexacarbonyl could be excluded in the case of rhenium complex 1 .

In principle, the method described in this article for very dilute solutions could be developed to a convenient alternative of some types of photochemical reactions. The main problem in achieving this goal is obviously the proper adjustment of substrate concentrations and diffusion layer thicknesses for preparatively resonable net chemical reactions, and, of course, more examples in inorganic or organic chemistry have to be found that show this interesting electrochemical behavior.

Acknowledgment. Financial support of this work by the Deutsche Forschungsgemeinschaft and the Fonds der Chemischen Industrie is gratefully acknowledged.

Registry No. 1, 55615-49-1; 2, 55658-97-4; 3, 13007-92-6; 4, 15228 38-3.

(12) Picket, C. J.; Pletcher, D. J. J. Chem. Soc., Dalton Trans. 1976, 749

(13) Vogler, A. In "Concents in Inorganic Photochemistry"; Adamson, A W., Fleischauer, P. D., Eds.; Wiley-Interscience Publishers: New York, 1975; Chapter 6 . 